\title{
LUNG DISEASES AMONG THE SHEFFIELD GRINDERS.
}

\author{
By HAROLD SOURFIELD, M.D. \\ Medical Officer of Health, Sheffield.
}

\begin{abstract}
T' $\mathrm{T}$ has generally been accepted by medical opinion that men who have 1 to work at certain occupations, which expose them to the inhaling of dust, are specially liable to die from a form of lung disease. It has also been generally accepted that this liability varies according to the nature of the dust inhaled; thus the effect mentioned has been observed in the case of the steel grinder and the gannister miner, and not in the case of the coal miner. It is now recognised that the lung disease which kills these workers, even if it begins as fibroid disease, ultimately becomes tubercular.
\end{abstract}

The table on p. 458 shows the death-rate among the Sheffield grinders and cutlers. At the top of the list are placed the grinders who use the largest proportion of dry stones. At the bottom of the table is given, for purposes of comparison, the death-rate among all males over 20 years of age. It will be noticed that the death-rate from phthisis among grinders is enormously high, and affects both wet and dry grinders.

In the Annual Report of the Chief Inspector of Factories and Workshops for the year 1900, there is a report by Dr. T. M. Legge on Gannister Miners' Disease. On p. 485 there is a table giving the cleaths for 10 years of the workers at one gannister mine, and it is there shown that of the 76 deaths, of which the causes are recorded, 64 were due to phthisis and gannister miners' disease; 7 to respiratory diseases; 1 to an accident; and 4 to other causes. In spite of this extraordinary mortality from phthisis, Dr. Legge, after examining a number of the workers, makes the following statement:-

"The physical development of nearly all the men examined was remarkably good, and even among the gannister workers conveyed no idea of the extent to which the lungs might become damaged by the dust."

vor. $\mathbf{x x x}$. No. 10 . 


\section{City of Shefrield.}

Mortality in the Grinding Trade and its Branches, also in the Cutlery Trade during eight years, 1901 to 1908, from All Causes, and from Phthisis and Diseases of the Respiratory System.

\begin{tabular}{|c|c|c|c|c|c|c|c|c|c|c|c|}
\hline \multirow{3}{*}{\multicolumn{2}{|c|}{ Trade and Branch. }} & \multirow{3}{*}{ 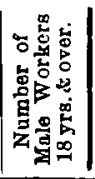 } & \multirow{2}{*}{\multicolumn{3}{|c|}{$\begin{array}{l}\text { No. of Grindstones } \\
\text { and Glazers. }\end{array}$}} & \multicolumn{6}{|c|}{ Deaths. } \\
\hline & & & & & & \multicolumn{2}{|c|}{ All Causes. } & \multicolumn{2}{|c|}{ Phthisis. } & \multicolumn{2}{|c|}{$\begin{array}{l}\text { Respirat'ry } \\
\text { Diseases. }\end{array}$} \\
\hline & & & 这离 & A & 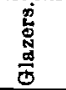 & No. & 要 & No. & 象 & No. & 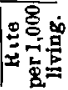 \\
\hline & & & & & & & per ann & & perand & & pe \\
\hline GRINDING & ... & 3941 & 3280 & 693 & 2325 & 966 & $30 \cdot 6$ & 480 & $15 \cdot 2$ & 174 & $5 \cdot 5$ \\
\hline Forks and Steels & $\ldots$ & 96 & - & 92 & 84 & 31 & $40 \cdot 4$ & 17 & $22 \cdot 1$ & 3 & $3 \cdot 9$ \\
\hline Augers, etc. ... & $\ldots$ & 54 & 6 & 46 & 43 & 10 & $23 \cdot 1$ & $y$ & 20.8 & 1 & $2 \cdot 3$ \\
\hline Surgical Instruments & 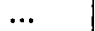 & 28 & 16 & 11 & 28 & 9 & $4 \sqrt{2}$ & 5 & 223 & 3 & $13 \cdot 4$ \\
\hline Scissors & $\ldots$ & 194 & 176 & 102 & 155 & 70 & $45 \cdot 1$ & 38 & 24.5 & 17 & 11.0 \\
\hline Razors. & $\ldots$ & 413 & 250 & 137 & 263 & 102 & $30 \cdot 9$ & 41 & $12 \cdot 4$ & 21 & $6 \cdot 4$ \\
\hline Edge Tools & $\ldots$ & 279 & 289 & 60 & 218 & 63 & $28 \cdot 2$ & 40 & 17.9 & 7 & $3 \cdot 1$ \\
\hline Knives-Table and Spring & & 1518 & 1302 & 202 & 1012 & 362 & $29 \cdot 8$ & 173 & $14 \cdot 2$ & 67 & $5 \cdot 5$ \\
\hline Sheep Shears $\ldots$. & $\ldots$ & 143 & 86 & 7 & 68 & 42 & $36 \cdot 7$ & 29 & $25 \cdot 3$ & 5 & $4 \cdot 4$ \\
\hline Agricultural \& Mining Impl & ements & 156 & 128 & 4 & 71 & 1 & $0 \cdot 8$ & - & - & - & - \\
\hline Hammers, Vices, Anvils, etc & c... & 53 & 28 & - & 31 & 5 & $11 \cdot 8$ & 1 & $2 \cdot 4$ & 1 & $2 \cdot 4$ \\
\hline Saws $\quad \ldots$ & $\ldots$ & 216 & 296 & - & 120 & 49 & 28.4 & 17 & $9 \cdot 8$ & 6 & $3 \cdot 5$ \\
\hline Seythes and Sickles ... & $\ldots$ & 40 & 45 & - & 12 & 12 & $37 \cdot 5$ & 8 & $25 \cdot 0$ & 3 & $9 \cdot 4$ \\
\hline Files and Rasps & $\ldots$ & 378 & 394 & - & 10 & 97 & $32: 1$ & 55 & $18 \cdot 2$ & 15 & $5 \cdot 0$ \\
\hline Miscellaneous... & $\cdots$ & 373 & 264 & 32 & 210 & 113 & $37 \cdot 9$ & 47 & $15 \cdot 8$ & 25 & $8 \cdot 4$ \\
\hline Cutifery & $\cdots$ & 3889 & - & - & - & 928 & $29 \cdot 8$ & 184 & $5 \cdot 9$ & 220 & $7 \cdot 1$ \\
\hline ALL MaLES (20 and over) & & 121000 & - & - & - & 16299 & $16 \cdot 4$ & 2705 & 27 & 3323 & $3 \cdot 3$ \\
\hline
\end{tabular}

In the following table a comparison is given of the death-rates among the grinders and cutlers and among other groups of Sheffield workers :-

\section{City of Shefrithd.}

Mortality in Certain Trades from All Causes, and from Phthisis and Respiratory Diseases during eight year's, 1901-1908.

\begin{tabular}{|c|c|c|c|c|c|}
\hline \multirow{2}{*}{ Trade. } & \multicolumn{2}{|c|}{ Workers. } & \multicolumn{3}{|c|}{$\begin{array}{l}\text { Average Annual Death-Rate } \\
\text { Per } 1,000 \text { Living. }\end{array}$} \\
\hline & Number. & Age. & All causes. & Phthisis. & $\begin{array}{l}\text { Respiratory } \\
\text { Dlseases. }\end{array}$ \\
\hline 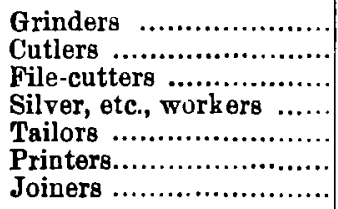 & $\begin{array}{r}3941(3) \\
3889(3) \\
1850(\mathscr{Z}) \\
2380(\mathscr{2}) \\
941(1) \\
487(\mathscr{2}) \\
2286(1)\end{array}$ & $\begin{array}{l}18 \text { and over } \\
18 \text { and over } \\
20 \text { and over } \\
20 \text { and over } \\
15 \text { and over } \\
20 \text { and over } \\
15 \text { and over }\end{array}$ & $\begin{array}{l}30 \cdot 6 \\
29 \cdot 8 \\
29 \cdot 9 \\
25 \cdot 9 \\
20 \cdot 9 \\
16 \cdot 7 \\
14 \cdot 1\end{array}$ & $\begin{array}{r}15 \cdot 2 \\
5 \cdot 9 \\
5 \cdot 4 \\
5 \cdot 4 \\
1 \cdot 6 \\
3 \cdot 3 \\
1 \cdot 8\end{array}$ & $\begin{array}{l}5 \cdot 5 \\
7 \cdot 1 \\
5 \cdot 2 \\
4 \cdot 5 \\
3 \cdot 7 \\
3 \cdot 1 \\
2 \cdot 8\end{array}$ \\
\hline Alu Males .................. & $124000(1)$ & 20 and over & $16 \cdot 4$ & $2 \cdot 7$ & $3 \cdot 3$ \\
\hline
\end{tabular}

The numbers employed shown in the above Table have been taken from sources as indicated by the bracketed number, as follows:-

(1) Census Report 1901.

(2) 'Trades Union Officials' and Manufacturers' Returns, 1906.

(3) Home Office (Factory Department) Return, corrected for workers outside city, 1908. 
As the result of a recent examination of Sheffield grinders conducted by Dr. Collis on behalf of the Home Office, and by Dr. Barnes on behalf of the employers, the evidence as to the presence of fibroid disease was inconclusire. It would appear that fibroid disease in its carly stages does not produce marked physical signs, or that a man may hold a considerable amount of stone, steel, and gannister dust in his lungs without developing fibroid disease.

The populations of the grinders and cutlers are taken from the recent census made by the Home Office, the populations of the tailors and joiners are taken from the 1901 census, and that of the printers from Trades Union returns, 1906.

It is difficult to combat the idea that the long-continued exposure to the dust in the case of grinders predisposes them to take tuberculosis of the lung. Nearly half of the grinders die from tuberculosis of the lungs, whereas only one-sixth of the adult males in Sheffield die from that disease.

Probably most people who are greatly predisposed to tuberculosis of the lung are sufficiently exposed to the risks of infection to contract the disease and die from it. It seems to me fair, therefore, to assume that the one-sixth of the male population who die from tuberculosis of the lungs inclucles nearly all those males who are greatly predisposed to the disease. No doubt the one-sixth also includes cases who are not specially predisposed, but who are exposed to long-continued and intimate sources of infection. It is also fair to assume that a large proportion of the five-sixths of the ordinary male population who do not die of tuberculosis of the lung have a strong resistance against that disease. It nust be remembered that many of these people have to live with consumptives, in many cases to occupy the same bedroom, or to sleep in the same bed, and yet they fail to die from the disease.

The grinders are originally men of good physique, and I think it is fair to assume that they include just as large a proportion of persons strongly resistant to tuberculosis as the ordinary male population, and yet half the grinders die from tuberculosis!

The circumstances of their occupation must therefore be such as to enable the tubercle bacillus to overcome many grinders endowed with a strong resistance. I cannot help thinking that the predisposing effect of the dust on the lung is a very important one, and my opinion is strengthened by the fact that tuberculosis of the lung is comparatively rare among women in Sheffield, and that the grinder does not infect 
the members of his own family at home in the same way as he does his fellow workmen. Surely there can be no more subtle method of infection than sleeping in the same bed with a patient and being exposed night after night to his cough-spray, and surely the grinder would infect his wife more easily than his fellow workmen were it not for the predisposing effect of the dust.

At the recent inquiry held in Sheffield the theory was advanced that fibrosis of the lung actually protected the worker against tuberculosis, and by its presence caused the tubercular disease to run a slower course than in a healthy lung. This opinion appears to be founded on the theoretical observation that if a tuberculous focus in the lung becomes healed the method adopted by nature is to build a wall of fibrous tissue round it. I should like to make a few observations on this theory.

In the first place there are no data to show that a person with fibrosis of the lungs takes longer to succumb to tuberculosis of the lungs than a person with a lung originally healthy. It would he difficult to obtain data. A number of fibroid cases would require to have their sputum examined at regular intervals in order to mark the interval between tubercular infection and death. After that had been done it would be difficult to obtain a standard for purposes of comparison from persons with lungs originally healthy. The duration of tuberculosis of the lung depends on so many other different factors. Agrain, it is to be expected that tuberculosis of the lungs in the case of many grinders will run a very slow course, because, as I have already shown, the grinders attacked must include many men who are endowed with a great natural resistance to the attacks of the tubercle bacillus. Fen if it could be shown that the tubercle bacillus does not flourish readily in that portion of the lung: which is actually affected by fibroid disease, is not the remaining healthy lung, by the fact that it is being over-worked, rendered more liable to attack?

It was suggested at the Sheffield inquiry that the greatest harm is done by the consumptive grinder spitting in the trough in which the wet stone revolves, and by the infected water being subsequently sprayed into the air. If this theory were correct, one would expect the wet grinders to be more affected than the dry grinders. This, however, is not so.

I do think there is not anything in the gannister miners' occupation (which is even more fatal as regards the causation of tuberculosis of the lung than the grinder's) which would take the place of the spray given off by the wet stone. I think that the suggestion with regard to the spray is a probable explanation as to why the wet grinders are nearly as bad 
as the dry, but also that this is a more subtle method of infection than sharing a bed with a patient in the late stages of the disease.

As regards prevention, I am of opinion that attention should not be solely devoted to the removal of dust hy fans, but that everything possible should be done (1) to improve the cleanliness, lighting, and ventilation of the grinders' hulls, (2) to control the careless spitting of the workers, a large proportion of whom must continue to be infectious until a great alteration has been effected in their industry, and (3) to encourage the workers to take an interest in their own health by temperance, regnlar meals, getting plenty of fresh air in their off time, etc.

Simple instructions on health matters should be issued to the grinclers making it clear to them that improvements in the future depend largely upon their own efforts. These instructions should be issued with the authority of the Home Office, and posted up in the various grinding hulls. 